\title{
Laparoscopic repair of perforated duodenal ulcer: a comparison with the open surgical technique
}

\author{
Ahmed Bahgat Abdul Latif, ${ }^{1}$ MBBCH, Magdy Mahmoud Moustafa, ${ }^{1}$ MD, Osama Fathy Ibrahim Al- \\ Mezaien, ${ }^{1} \mathrm{MD}$.
}

* Corresponding Author:

Ahmed Bahgat Abdul Latif

ahmed.bahgat2017@gmail.com

Received for publication October 29, 2021; Accepted January 16, 2022; Published online January $16,2022$.

Copyright The Author published by Al-Azhar University, Faculty of Medicine, Cairo, Egypt. Users have the right to read, download, copy, distribute, print, search, or link to the full texts of articles under the following conditions: Creative Commons AttributionShare Alike 4.0 International Public License (CC BY-SA 4.0).

doi: $10.21608 /$ aimj.2022.103320.1632.

${ }^{1}$ General Surgery Department, Faculty of Medicine, Al-Azhar University, Cairo, Egypt.

\begin{abstract}
Background: One of the most prevalent disorders seen in patients who present to the emergency rooms with severe abdominal pains is duodenal ulcer perforation. Accurate diagnosis and immediate repair should be done as early as possible. Surgical repair using Graham omental patch can be achieved either by open technique or done laparoscopically. The comparison between open and laparoscopic repair were compared and evaluated in our study.

Aim of the study Comparison between the efficacy, advantages, disadvantages, limitations, post-operative pain, and complications leading to morbidity and death, length of stay in hospital, recurrence and return to normalcy in open and laparoscopic procedures.

Patients and Methods: From January 2021 to July 2021, the Department of General Surgery at Al-Azhar University Hospitals in Cairo, Egypt, carried out this prospective study. It included 30 patients with perforated duodenal ulcer. Those patients have been classified into 2 groups that were equal in size, first group underwent laparoscopic procedure while other group submitted to open repair. Comparison was applied between the two groups.

Results: Laparoscopy repair outperforms open repair in terms of postsurgical pains, bowel habit return, initiation of oral diet, and hospital duration of stay. However, there is a longer period and a larger prevalence of intra-abdominal collection. Post-operative complications are more common with open repairs.

Conclusion: Laparoscopic repair of perforated peptic ulcers is a safe emergency treatment with several benefits, including reduced postsurgical pain, earlier bowel habit return, earlier initiation of oral diet, shorter hospital stays, better esthetic results, as well as fewer postsurgical complications.
\end{abstract}

Keywords: Perforated duodenal ulcer.

Disclosure: The authors have no financial interest to declare in relation to the content of this article. The Article Processing Charge was paid for by the authors.

Authorship: All authors have a substantial contribution to the article.

\section{INTRODUCTION}

A duodenal ulcer is a form of peptic ulcer that occurs in the duodenum towards the beginning of the small intestine. Peptic ulcer is portions of the stomach and duodenum lining that have eroded, resulting in abdominal soreness, potential hemorrhage, as well as other gastrointestinal symptoms. A stomach infection caused by the Helicobacter pylori bacteria is the most prevalent cause of duodenal ulcers. ${ }^{1}$

Despite the usage of numerous anti-ulcer agents and eradication treatments, duodenal ulcer perforation remains a prevalent consequence of duodenal ulcer illness. It is among the most prevalent reasons for admittance to a hospital in the world, especially in developing countries. $^{2}$
Perforated duodenal ulcer is primarily an illness of young males, but due to increased smoking in females as well as the usage of nonsteroidal antiinflammatory drugs (NSAIDs) across all age categories, it is now prevalent in the entire adult population. $^{3}$

The prevalence of peptic ulcer illness and concomitant complications has reduced considerably since the invention of curative medicinal therapy for H. pylori, and final operative treatments are now rarely undertaken. Interestingly, the rate of perforation has not been reduced, implying that the pathogenesis of perforated peptic ulcer illness may be complicated by multiple causes. Infection with $\mathrm{H}$. pylori, smoking, usage of NSAIDs, and a history of 
peptic ulcer are all recognized statistically significant risk factors for perforation. ${ }^{4}$

Peptic ulcers commonly occur in the duodenum's first section and the stomach's lesser curvature, but they can also appear in the stoma following stomach surgery, esophagus, and even Meckel's diverticulum. Duodenal ulcer perforation is the third most prevalent abdominal emergency, following acute appendicitis and acute intestinal blockage. ${ }^{5}$

Duodenal ulcer symptoms could be constant or sporadic, and the disease's progression differs from person to person. If $\mathrm{H}$. pylori is responsible for the ulcer, the symptoms will last as long as the infection is not treated. Some individuals with duodenal ulcers experience no symptoms at all, whereas others experience severe nausea and vomiting, as well as scorching pain. ${ }^{6}$

The mainstay of therapy for a perforated duodenal ulcer is surgery, which involves sealing the perforation with or without the use of omental patches. The surgical intervention for a perforated duodenal ulcer is without controversy, but the optimum surgical strategy is still up for debate. The aim of the research would have been to look at the viability of laparoscopic treatment of duodenal perforation and make a comparison between it and traditional open repair in aspects of operational time, postsurgical pain, stay in hospital, and postsurgical complications in our set-up. ${ }^{7}$

\section{PATIENTS AND METHODS}

This is a prospective study in which 30 patients having perforated duodenal peptic ulcers have been admitted to the General Surgery Department at AlAzhar University Hospitals (Al-Hussein and Sayed Galal) between January and July 2021. All patients were given a full assessment that included a detailed medical history, a thorough physical exam, laboratory tests, and an imaging study Chest X-ray erect was performed to all patients.

All patients had pre-operative Abdominal X-ray Erect and Abdominal Ultrasound. Patients were excluded if they were $<15$ years old and $>70$ years old, had a clinical presentation that lasted more than two days, were in shock, or had a systolic BP of $<90$ $\mathrm{mm} \mathrm{Hg}$ that won't be enhanced following hydration. Patients with clinically sealed perforations, contraindications to laparoscopy, prior upper abdominal operations, and perforations other than the duodenum were converted to open surgery intraoperatively.

The patients were randomized into two groups using a random serial number method: group A included 15 patients for laparoscopic surgery, while group B included 15 patients for open repair. Laparoscopic repair was done in all patients by the same surgical team using the standard technique of operation. The operative time was calculated from the start of the incision until placement of the last suture. The outcome and complications of laparoscopic repair, the conversion rate to an open operation, the surgical time, as well as the duration of stay in the hospital have all been recorded. All patients were followed up and instructed to notify the surgeon if there were any complications.

\section{Statistical methods}

SPSS version 15 has been utilized to analyze the data gathered (SPSS Inc., Chicago, IL, USA). Quantitative data has been expressed as mean \pm SD, whereas qualitative data has been expressed as number and percentage (\%). The independent student test has been utilized to identify the significance of the difference in quantitative data, whereas the Chi square or Fisher's exact test has been utilized to identify the significance of the difference in qualitative data. A statistically significant p-value of $<0.05$ was determined.

\section{RESULTS}

In terms of sex, history of PU disease, NSAID intake, \& smoking, there were no statistically significant differences ( $\mathrm{p}$-value > 0.05) among the groups studied (Table 1).

In terms of clinical presentation, this table reveals that there is no statistically significant difference (pvalue $>0.05$ ) among the studied groups (Table 2).

In terms of operative time and post-operative pain score, this table shows a highly statistically significant difference ( -value $<0.001)$ among the studied groups (Table 3).

In terms of post-operative hospital stay and postoperative start of oral intake, this table reveals a highly statistically significant difference (p-value < 0.001) among the studied groups (Table 4).

This table shows results of post-operative complications. In terms of suture leakage, intraabdominal collections, and incisional hernia, there was no statistically significant difference (p-value > 0.05 ) among the studied groups. In terms of postoperative wound infection and post-operative chest infection, there were statistically significant differences (p-value 0.05) among the studied groups. (Table 5).

\section{DISCUSSION}

In the immediate or acute post-operative phase, a seroma is an accumulation of serous fluid formed after the development of skin flaps during mastectomy or in the axillary dead space. ${ }^{10}$

The prevalence and treatment of peptic ulcers have evolved dramatically since the initial surgical operations were performed less than a decade earlier.

First, the identification of $\mathrm{H}$. pylori, which is now known to be related to $95 \%$ of instances of duodenal 
ulcers, has made significant progress in understanding the disease process etiology.

Second, the development of pharmaceutical H2receptor antagonists as well as proton pump inhibitors implies that acid secretion in the stomach can now be controlled without invasive and frequently debilitating surgical operations. ${ }^{8}$

\begin{tabular}{|c|c|c|c|c|c|c|c|}
\hline \multirow{2}{*}{ Sex } & \multirow{3}{*}{$\begin{array}{l}\text { Male } \\
\text { female }\end{array}$} & \multicolumn{2}{|c|}{ Group A $(N=15)$} & \multicolumn{2}{|c|}{ Group B $(N=15)$} & \multirow{3}{*}{$\begin{array}{l}\text { Stat. test } \\
\mathrm{X} 2=0.18\end{array}$} & \multirow{2}{*}{$\begin{array}{l}\text { P-value } \\
0.666 \mathrm{NS}\end{array}$} \\
\hline & & 12 & $80 \%$ & 11 & $73.3 \%$ & & \\
\hline & & 3 & $20 \%$ & 4 & $26.7 \%$ & & \\
\hline \multirow{2}{*}{$\begin{array}{l}\text { History of peptic ulcer } \\
\text { disease }\end{array}$} & No & 9 & $60 \%$ & 8 & $53.3 \%$ & \multirow[t]{2}{*}{$X 2=0.13$} & \multirow[t]{2}{*}{$0.712 \mathrm{NS}$} \\
\hline & yes & 6 & $40 \%$ & 7 & $46.7 \%$ & & \\
\hline \multirow[t]{2}{*}{ NSAID intake } & No & 11 & $73.3 \%$ & 12 & $80 \%$ & \multirow[t]{2}{*}{$\mathrm{X} 2=0.18$} & \multirow[t]{2}{*}{$0.666 \mathrm{NS}$} \\
\hline & Yes & 4 & $26.7 \%$ & 3 & $20 \%$ & & \\
\hline \multirow[t]{2}{*}{ Smoking } & No & 5 & $33.3 \%$ & 6 & $40 \%$ & \multirow[t]{2}{*}{$X 2=0.14$} & \multirow[t]{2}{*}{$0.704 \mathrm{NS}$} \\
\hline & Yes & 10 & $66.7 \%$ & 9 & $60 \%$ & & \\
\hline
\end{tabular}

Despite such advancements, emergency presentations with bleeding or perforation still happen on a regular basis, and it is the surgical trainee's responsibility to master the basics of patient treatment in such instances.

Table 1: Comparison between studied groups as regard sex, History of PU disease, NSAID intake \& Smoking.

\begin{tabular}{|lllllll|}
\hline & \multicolumn{2}{l}{$\begin{array}{l}\text { Group A } \\
(\mathbf{N = 1 5})\end{array}$} & \multicolumn{2}{l}{$\begin{array}{l}\text { Group B } \\
(\mathbf{N = 1 5})\end{array}$} & X2 & P-value \\
\hline Severe abdominal pain & 15 & $100 \%$ & 15 & $100 \%$ & 0.0 & $1.0 \mathrm{NS}$ \\
\hline Abdominal distention & 10 & $66.7 \%$ & 11 & $73.3 \%$ & 0.15 & $0.690 \mathrm{NS}$ \\
\hline Vomiting & 8 & $53.3 \%$ & 8 & $53.3 \%$ & 0.0 & $1.0 \mathrm{NS}$ \\
\hline Abdominal tenderness & 12 & $80 \%$ & 14 & $93.3 \%$ & 1.15 & $0.282 \mathrm{NS}$ \\
\hline Classical signs of peritonitis & 11 & $73.3 \%$ & 12 & $80 \%$ & 0.18 & $0.666 \mathrm{NS}$ \\
\hline
\end{tabular}

Table 2: Comparison between studied groups as regard clinical presentation.

\begin{tabular}{|cccccc|}
\hline & & $\begin{array}{c}\text { Group A } \\
(\mathbf{N = 1 5})\end{array}$ & $\begin{array}{c}\text { Group B } \\
(\mathbf{N = 1 5})\end{array}$ & Stat. test & P-value \\
\hline Operative time (min) & Mean & 144.2 & 104.9 & MW =0.0 & $<0.001 \mathrm{HS}$ \\
& \pm SD & 7.9 & 9.3 & & \\
Post-operative pain score & Mean & 1.26 & 5.8 & MW $=0.0$ & $<0.001 \mathrm{HS}$ \\
& \pm SD & 0.4 & 0.7 & & \\
\hline
\end{tabular}

Table 3: Comparison between studied groups as regard operative time and post-operative pain using the Numerical pain scale scoring system (0-10).

\begin{tabular}{llllll} 
& & $\begin{array}{l}\text { Group A } \\
(\mathrm{N}=15)\end{array}$ & $\begin{array}{l}\text { Group B } \\
(\mathrm{N}=15)\end{array}$ & Stat. test & P-value \\
\hline $\begin{array}{l}\text { Post-operative } \\
\text { hospital stay (days) }\end{array}$ & Mean & 3.66 & 5.9 & MW =6 & $<0.001 \mathrm{HS}$ \\
\hline $\begin{array}{l}\text { Post-operative start } \\
\text { of oral intake (days) }\end{array}$ & Mean & 0.8 & 0.7 & & \\
& $\pm \mathrm{SD}$ & 0.43 & 3.66 & $\mathrm{MW}=32.5$ & $<0.001 \mathrm{HS}$ \\
\hline
\end{tabular}

Table 4: Comparison of the study groups' post-operative hospital stays and oral intake start times.

\begin{tabular}{llllllll}
\hline & & $\begin{array}{l}\text { Group A } \\
(\mathrm{N}=15)\end{array}$ & & $\begin{array}{l}\text { Group B } \\
(\mathrm{N}=15)\end{array}$ & & Stat. test & P-value \\
\hline Suture leakage & No & 14 & $93.3 \%$ & 14 & $93.3 \%$ & & $1.0 \mathrm{NS}$ \\
& Yes & 1 & $6.7 \%$ & 1 & $6.7 \%$ & $\mathrm{X} 2=0.0$ & \\
Intra-abdominal & No & 14 & $93.3 \%$ & 15 & $100 \%$ & & \\
collection & Yes & 1 & $6.7 \%$ & 0 & $0 \%$ & $\mathrm{X} 2=1.03$ & $0.309 \mathrm{NS}$ \\
Incisional hernia & No & 15 & $100 \%$ & 13 & $86.7 \%$ & & \\
& Yes & 0 & $0 \%$ & 2 & $13.3 \%$ & $\mathrm{X} 2=2.14$ & $0.143 \mathrm{NS}$ \\
Wound infection & No & 15 & $100 \%$ & 11 & $73.3 \%$ & $\mathrm{X} 2=4.6$ & $0.031 \mathrm{~S}$ \\
& Yes & 0 & $0 \%$ & 4 & $26.7 \%$ & & \\
Chest & No & 14 & $93.3 \%$ & 9 & $60 \%$ & $\mathrm{X} 2=4.65$ & $0.030 \mathrm{~S}$ \\
Infection & Yes & 1 & $6.7 \%$ & 6 & $40 \%$ & &
\end{tabular}


Table 5: Comparison between studied groups as regard post-operative complications.

Laparoscopic repair of perforated peptic ulcers is an appealing alternative. The treatment not only permits the identification of the perforation's location and pathology, but it also permits perforation closure and peritoneal lavage, similar to open surgery, but without the need for a big incision in the upper abdomen.

The goal of this study is to discuss the efficacy, advantages, disadvantages, limitations, postoperative pain, and complications leading to morbidity and death, length of stay in hospital, recurrence, and return to normalcy between open and laparoscopic procedures and to arrive at a conclusion as to the best modality of treatment between both types.

The present study has been carried out as a controlled randomized study and conducted in the elective surgery theatres of the department of general surgery at Al-Hussein \&Sayed Galal hospitals including 30 patients of mean age of $(41.06 \pm 4.8)$ years and dominance of male gender. These demographic features revealed no statistically significant differences across the two groups. The study population consisted of 30 patients who were allocated into two groups at random; the first one submitted to laparoscopic repair of the perforation, and the 2 nd group submitted to open repair .

Bertleff and his colleagues agree with us that is no significant gender-related difference in between two groups. ${ }^{9}$

In this research, $40 \%$ of patients in the laparoscopic group had peptic ulcer history, compared to $46.7 \%$ in the open group. There were no significant differences in such factors between the laparoscopic and open groups. The history of NSAID intake was $26.7 \%$ in the laparoscopic group and $20 \%$ in the open group. The history of smoking was $66.7 \%$ in the laparoscopic group and $60 \%$ in the open group.

In their retrospective investigation, Karimian and his colleagues discovered that there were no significant differences in the peptic ulcer history in the laparoscopic group $(25.9 \%)$ versus the open group $(11.1 \%)$, the history of NSAID intake in the laparoscopic group (32\%) versus the open group $(24 \%)$, and smoking history in the laparoscopic group $(68 \%)$ versus the open group $(64 \%) .{ }^{10}$

The most prevalent presenting symptoms in our research were the abrupt onset of acute epigastric pain $(100 \%)$ followed by distention of the abdomen (73.3\%) and vomiting (50.3\%). Patients with abdominal pain and traditional symptoms of peritonitis were found in $93.3 \%$ and $80 \%$ of cases, respectively.

The most prevalent presenting symptoms, according to Philipo and his colleagues, were the abrupt start of acute epigastric pain (97.6\%), distention of the abdomen (76.2\%), and vomiting (36.9\%) in sufferers.
Tenderness in the abdomen and classic symptoms of peritonitis have been shown in $88.1 \%$ and $66.7 \%$ of cases, respectively. ${ }^{11}$

With a conversion rate of $13.3 \%$, two cases in the laparoscopic group have been converted to open surgery in this research. The huge size of the perforation in 1 case $(>2 \mathrm{~cm})$ and difficulties inserting the sutures via the friable edges in another case were the causes of conversion. In 2013.

In a non-randomized prospective trial of 61 cases, Sreeramulu and his colleagues observed a nearly same conversion rate $(9.6 \%)$, owing to significant perforation $(>2 \mathrm{~cm})$ and dense adhesion. ${ }^{12}$

In this study, the surgical time for the laparoscopic groups was significantly longer. In comparison to the open group (104.9 $\mathrm{min}$ ), the laparoscopic group's mean surgical time was (144.2 $\mathrm{min}$ ).

Other studies have revealed a much longer operational time for laparoscopic repair.

Suture leakage was observed in two patients in this study, one for each group (6.7\%), but there was no statistical significance. Ricky and his co-workers found the same outcome in a study they conducted.

However, a study conducted by Bertleff and coworkers indicated that the laparoscopic group (3\%) had a greater rate of leakage than the open group $(0 \%)$, but leakage was mostly seen in the sutureless repair group or in the group that did not utilize omentoplasty frequently. Nevertheless, the leakage rate reached zero in the study performed by Gyou and his co-workers. ${ }^{9,13}$

Following open treatment of perforated peptic ulcers, wound complications in hospitalization were the most frequent morbidity, with a rate of $26.7 \%$ versus $0 \%$ in the laparoscopic group. The difference $(\mathrm{p}=0.031)$ is statistically significant. The complications of the wounds included shallow operative site infection, wound seroma, as well as dehiscence of the wound.

The open group had a greater frequency of wound complications, according to Katkhouda and Mehendale. ${ }^{14,15}$

The difference in the first two studies did not reach statistical significance, but it did in the second two studies.

However, a meta-analysis conducted by Lau and colleagues proved that in the repair of perforated peptic ulcers, the laparoscopic group had a significantly decreased rate of wound complications than the open group $(\mathrm{p}=0.036){ }^{16}$

We discovered that laparoscopic repair of perforated peptic ulcers is preferable to open surgery in terms of 
postsurgical pain, bowel habit return, beginning of oral diet, and hospital length of stay, based on statistical analysis. Laparoscopic repair currently has two major disadvantages: a lengthier operational time and the difficulty of repairing large perforations. The main disadvantages of open surgery are a higher likelihood of chest infection, wound complications, and a less aesthetic result.

\section{CONCLUSION}

Laparoscopic repair of perforated peptic ulcers of the duodenum is a safe emergency treatment with several benefits, including reduced postsurgical pain, earlier bowel habit return, earlier initiation of oral diet, shorter hospital stay, better esthetic results, as well as fewer postsurgical complications.

\section{REFERENCES}

1. Milosavljević T, Kostić- Milosavljević M, and Jovanović I. complications of peptic ulcer disease. Diestive diseases. 2011; 29 (5): 491-3.

2. Moller MH, Adamsen S, Wøjdemann M, et al. Perforated peptic ulcer: how to improve outcome? Scand J Gastroenterol. 2015; 44:1522.

3. Motewar A, Tilak M, Patil D, et al. Laparoscopic versus open management of duodenal perforation: a comparative study at a District General Hospital. Prz Gastroenterol. 2013; 8(5):315-9.

4. Ramsoekh D, Leerdam VME, Rauws EA, et al. Outcome of peptic ulcer bleeding, nonsteroidal anti-inflammatory drug use, and Helicobacter pylori infection. Clin Gastroenterol Hepatol. 2005; 3(9):859-64.

5. Thorsen K, Glomsaker TB, von Meer A, et al. Trends in diagnosis and surgical management of patients with perforated peptic ulcer. $J$ Gastrointest Surg. 2011; 15:1329-35.

6. Najm WI. Peptic ulcer disease. Primary care. 2011; 38 (3):383-94.

7. Deshmukh SN and Parikh HP. Open versus laparoscopic repair of perforated duodenal ulcer: a comparative study. Int Surg J. 2020; 7:1004-8.

8. Stewart DJ and Ackroyd R. Peptic ulcers and their complications. Surgery (oxford). 2011; 29 (11) 568-74.

9. Bertleff MJ, Lange JF and Johan FL. Laparoscopic correction of perforated peptic ulcer: first choice? A review of literature. Surg Endosc. 2010; 24(6): 1231-9.

10. Karimian F, Aminian A, Mirsharifi R, et al. perforated peptic ulcer, comparison between laparoscopic and open repair. Shiraz E medical journal. 2009; 10 (1), 20-6.

11. Philipo LC , Joseph BM , Koy M , et al. Clinical profile and outcome of surgical treatment of perforated PU. World journal of emergency surgery. 2011; 6 (1), 1-10.
12. Sreeramulu PN, Venka TS and Supreet CS. A comparative study of laparoscopic vs open surgery for the management of duodenal ulcer perforation. World J laparosc sur. 2013; 6, 11-4.

13. Gyou Ra Lee, Kyung Park and Sung kim. Laparoscopic primary closure, a better method of treatment of perforated peptic ulcer than open repair. Journal of minimally invasive surgery. 2012; 15:11-4.

14. Katkhouda N, Mavor E, Mason RJ, et al: laparoscopic repair of perforated duodenal ulcers. archives of surgery. 1999; 134 (8), 845-50.

15. Mehendale VG, Shenoy SN and Joshi AM. Laparoscopic versus open surgical closure of perforated duodenal ulcers. Indian journal of gastroenterology. 2002; 21 (6) 222-4.

16. Lau JY, Sung J, Hill C, et al. Systematic review of the epidemiology of complicated peptic ulcer disease: incidence, recurrence, risk factors and mortality. Digestion. 2011; 84:102-13. 